\title{
Atomic-Scale Insights on Large-Misfit Heterointerfaces in $\mathrm{LSMO} / \mathrm{MgO} / \mathrm{c}-\mathrm{Al}_{2} \mathrm{O}_{3}$
}

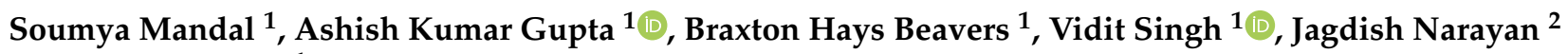 \\ and Ritesh Sachan ${ }^{1, *}$ \\ 1 Department of Mechanical and Aerospace Engineering, Oklahoma State University, \\ Stillwater, OK 74078, USA; smandal@okstate.edu (S.M.); ashish.gupta10@okstate.edu (A.K.G.); \\ braxton.beavers@okstate.edu (B.H.B.); vidit.singh@mst.edu (V.S.) \\ 2 Materials Science and Engineering, North Carolina State University, Raleigh, NC 27606, USA; \\ narayan@ncsu.edu \\ * Correspondence: rsachan@okstate.edu
}

check for updates

Citation: Mandal, S.; Gupta, A.K.; Beavers, B.H.; Singh, V.; Narayan, J.; Sachan, R. Atomic-Scale Insights on Large-Misfit Heterointerfaces in $\mathrm{LSMO} / \mathrm{MgO} / \mathrm{c}-\mathrm{Al}_{2} \mathrm{O}_{3}$. Crystals 2021, 11, 1493. https://doi.org/10.3390/ cryst11121493

Academic Editor: Zaoli Zhang

Received: 16 October 2021

Accepted: 28 November 2021

Published: 1 December 2021

Publisher's Note: MDPI stays neutral with regard to jurisdictional claims in published maps and institutional affiliations.

Copyright: (c) 2021 by the authors. Licensee MDPI, Basel, Switzerland. This article is an open access article distributed under the terms and conditions of the Creative Commons Attribution (CC BY) license (https:/ / creativecommons.org/licenses/by/ $4.0 /)$.

\begin{abstract}
Understanding the interfaces in heterostructures at an atomic scale is crucial in enabling the possibility to manipulate underlying functional properties in correlated materials. This work presents a detailed study on the atomic structures of heterogeneous interfaces in $\mathrm{La}_{0.7} \mathrm{Sr}_{0.3} \mathrm{MnO}_{3}$ (LSMO) film grown epitaxially on $\mathrm{c}-\mathrm{Al}_{2} \mathrm{O}_{3}$ (0001) with a buffer layer of $\mathrm{MgO}$. Using aberration-corrected scanning transmission electron microscopy, we detected nucleation of periodic misfit dislocations at the interfaces of the large misfit systems of $\mathrm{LSMO} / \mathrm{MgO}$ and $\mathrm{MgO} / \mathrm{c}-\mathrm{Al}_{2} \mathrm{O}_{3}$ following the domain matching epitaxy paradigm. It was experimentally observed that the dislocations terminate with $4 / 5$ lattice planes at the $\mathrm{LSMO} / \mathrm{MgO}$ interface and with $12 / 13$ lattice planes at the $\mathrm{MgO} / \mathrm{c}-\mathrm{Al}_{2} \mathrm{O}_{3}$ interface. This is consistent with theoretical predictions. Using the atomic-resolution image data analysis approach to generate atomic bond length maps, we investigated the atomic displacement in the $\mathrm{LSMO} / \mathrm{MgO}$ and $\mathrm{MgO} / \mathrm{c}-\mathrm{Al}_{2} \mathrm{O}_{3}$ systems. Minimal presence of residual strain was shown at the respective interface due to strain relaxation following misfit dislocation formation. Further, based on electron energy-loss spectroscopy analysis, we confirmed an interfacial interdiffusion within two monolayers at both $\mathrm{LSMO} / \mathrm{MgO}$ and $\mathrm{MgO} / \mathrm{c}-\mathrm{Al}_{2} \mathrm{O}_{3}$ interfaces. In essence, misfit dislocation configurations of the $\mathrm{LSMO} / \mathrm{MgO} / \mathrm{c}-\mathrm{Al}_{2} \mathrm{O}_{3}$ system have been thoroughly investigated to understand atomic-scale insights on atomic structure and interfacial chemistry in these large misfit systems.
\end{abstract}

Keywords: scanning transmission electron microscopy; lanthanum strontium manganese oxide; heterointerfaces; domain matching epitaxy; large misfit systems

\section{Introduction}

The nature of epitaxial growth and the control of defects in the thin film heterostructure are considered of significant importance for tuning next-generation electrical, optical, and magnetic devices [1,2]. Unlike their bulk counterparts, oxide thin films have a heterogeneous structure suitable for these applications [3]. The coupling states such as charge, orbitals, and lattice strain are susceptible to heterostructure perturbation leading to the emergence of new properties [4]. Studies on oxide thin film confirm that the presence of dislocation in heterostructure can alter the film properties $[5,6]$. The lattice strain and defects at the interface control the quality of the thin film and its associated functionalities [6,7].

A particularly intriguing correlated metal-oxide material is Lanthanum strontium manganese oxide $\left(\mathrm{La}_{0.7} \mathrm{Sr}_{0.3} \mathrm{MnO}_{3}\right.$ or LSMO) with a Curie temperature of $370 \mathrm{~K}[8,9]$. Studies show that the presence of the strain in epitaxial film can greatly affect the properties of LSMO [10-13]. It is well established that the misfit present at the interface introduces strain in the system and is gradually relieved after a few hundred monolayers. This result ensures the thin film properties are directly influenced by the interfacial defects. Although LSMO is typically grown on $\mathrm{SrTiO}_{3}$ (STO) or $\mathrm{MgO}$, the lattice misfit differs 
between $\mathrm{LSMO} / \mathrm{MgO}$ and LSMO/STO. LSMO and STO share similar crystal structures with a fractional lattice misfit of $\sim 0.79 \%$. Notably, the reported lattice misfit between the LSMO and MgO is greater than 7\% [10]. In both cases, the lattice parameter of LSMO is smaller and expands the film along the in-plane direction, resulting in compression in the out-of-plane direction. It has been reported that STO affects titanium-oxygen octahedral rotations that influence LSMO growth [10]. In addition, STO induces electronic softening of the Mn-O bond, which scatters the spin and negatively affects the properties of LSMO thin film [14-16]. Contrarily, $\mathrm{MgO}$ does not exhibit these types of phenomena. Substrates such as $\mathrm{MgO}$ have large lattice misfits with film and are energetically favorable to containing misfit dislocations that accelerate film relaxation. The misfit dislocations are nucleated on the film surface at a critical thickness and then relocate towards the interface. Therefore, complete film relaxation can be achieved within a few monolayers, thus allowing the subsequent film to grow relaxed or strain free. This process can be explained by domain-matching epitaxy (DME), where integral multiples of lattice constants match across film-substrate interfaces $[17,18]$. Studies show that many systems with large lattice misfits can be grown successfully on $\mathrm{MgO}$ (001) following the DME process [19-23]. In essence, the coupling effect, film-substrate thermal expansion difference, and the step terrace may increase difficulty in understanding the interfacial structure $[4,24]$.

The development of aberration-corrected electron microscopy made it possible to collect atomic resolution images [25]. An important characteristic of scanning transmission electron microscopy (STEM) is its capability of efficiently recording image contrast depending upon the lattice atomic number (Z). Interestingly, the atomic contrast does not vary with alterations in film thickness and imaging focus [26]. It is therefore simple to distinguish the atomic column and interfaces from the system. In this study, a detailed investigation of the interfacial structure was performed on the oxide heterostructure $\mathrm{LSMO} / \mathrm{MgO} / \mathrm{c}-$ $\mathrm{Al}_{2} \mathrm{O}_{3}$ utilizing aberration-corrected scanning transmission electron microscopy (STEM) together with electron energy-loss spectroscopy (EELS) measurements. Particularly, this study focuses on the misfit dislocations observed at the $\mathrm{LSMO} / \mathrm{MgO}$ and $\mathrm{MgO} / \mathrm{c}-\mathrm{Al}_{2} \mathrm{O}_{3}$ interfaces. A detailed examination of the interface shows the additional misfit strain can be accommodated within the DME framework by changing the periodicity of the dislocations. Therefore, strain is relieved from the system within a couple of monolayers following the application of DME concepts. This allows the misfit strain to be confined and engineered near the interface. As a result, the remaining film can grow defect and strain free. In addition, the execution of atomic bond length mapping ensures the strain-free growth of the film with exception to a small number of monolayers near the interface. Finally, EELS was performed for investigation and clarification of the interfacial chemistry between the subsequent film and substrate. This study signifies the importance of misfit dislocations in thin film, thus representing a promising pathway in the improvement of film quality and its associated properties.

\section{Experimental Methodology}

The LSMO and MgO thin films were grown epitaxially on the (0001) c- $\mathrm{Al}_{2} \mathrm{O}_{3}$ substrate using pulsed laser deposition technique with a $\mathrm{KrF}$ (wavelength $248 \mathrm{~nm}$ ) excimer laser. Base pressure inside the vacuum chamber prior to the deposition and sample-target distance were maintained at $\sim 5 \times 10^{-7}$ Torr and $\sim 4.5 \mathrm{~cm}$. Thin films of MgO and LSMO were deposited at laser energy densities $\sim 3.1 \mathrm{~J} / \mathrm{cm}^{2}$ and $\sim 1.7 \mathrm{~J} / \mathrm{cm}^{2}$, respectively, while maintaining a substrate temperature of $\sim 680^{\circ} \mathrm{C}(\mathrm{MgO})$ and $\sim 800^{\circ} \mathrm{C}(\mathrm{LSMO})$. The estimated thickness of deposited $\mathrm{MgO}$ and LSMO were $\sim 25 \mathrm{~nm}$ and $\sim 15 \mathrm{~nm}$, respectively. During the deposition, the oxygen partial pressure was maintained at $\sim 1 \times 10^{-3}$ Torr. The films were grown over c-cut sapphire (0001) with epitaxial MgO growing in (111) out-of-plane direction followed by LSMO in (110) growth direction. A detailed description of thin film synthesis is provided elsewhere $[10,27]$. The atomic-resolution electron microscopic investigations were performed using a fifth-order aberration-corrected scanning transmission electron microscope (STEM) (Nion UltraSTEM 200) operated at $200 \mathrm{KeV}$. The high-angle 
annular dark field (HAADF) imaging was acquired with an inner collection semi-angle of $65 \mathrm{mrad}$ at a probe current of $18 \pm 2 \mathrm{pA}$. The convergence semi-angle of the electron probe was $30 \mathrm{mrad}$. The EELS data were acquired with a collection angle of $48 \mathrm{mrad}$. The samples for STEM analysis were prepared by conventional mechanical thinning, precision polishing, and ion-milling in a liquid $\mathrm{N}_{2}$ environment $[28,29]$.

\section{Results and Discussion}

Figure 1a presents an overview HAADF image of the LSMO thin film grown on the $\mathrm{c}-\mathrm{Al}_{2} \mathrm{O}_{3}$ substrate with a $\mathrm{MgO}$ buffer layer using pulsed laser deposition. The LSMO film of thickness $\sim 15 \pm 1 \mathrm{~nm}$ is grown uniformly on the $\mathrm{MgO}$ buffer layer ( $25 \mathrm{~nm})$. Figure $1 \mathrm{~b}, \mathrm{c}$ subsequently illustrates the interface between $\mathrm{LSMO} / \mathrm{MgO}$ and $\mathrm{MgO} / \mathrm{c}-\mathrm{Al}_{2} \mathrm{O}_{3}$ illustrating the epitaxial film growth. The verification of epitaxial growth was performed by $x$-ray diffraction ( $\theta-2 \theta$ and $\Phi$-scan) studies on these films $[10,27]$. Figure $1 b$ shows the atomicresolution HAADF image consisting of LSMO film on $\mathrm{MgO}$. Since the intensity of the HAADF image is proportionally related with the atomic number of the elements with a dependence of $Z^{n}$, where $n=1.5$ to 2 [30], the atoms with the brightest intensity presents the $\mathrm{La} / \mathrm{Sr}$ atoms columns in the Figure $1 \mathrm{~b}$ and the less bright atoms in between them are the $\mathrm{Mn}$ atoms. On the other hand, the $\mathrm{Mg}$ atoms show the least intensity. The atomic arrangement, here, is viewed in LSMO (110) and MgO (112) surface normal directions. Figure 1c exhibits the atomic resolution HAADF image of the interface between the $\mathrm{MgO}$ buffer layer on the $\mathrm{c}-\mathrm{Al}_{2} \mathrm{O}_{3}$ substrate. The $\mathrm{Mg}$ atoms appear less luminous than the $\mathrm{c}-\mathrm{Al}_{2} \mathrm{O}_{3}$ atoms. The interface between $\mathrm{MgO}$ and $\mathrm{c}-\mathrm{Al}_{2} \mathrm{O}_{3}$ is well distinguished based on the atomic column intensity as well as the crystal structure orientations.

(a)

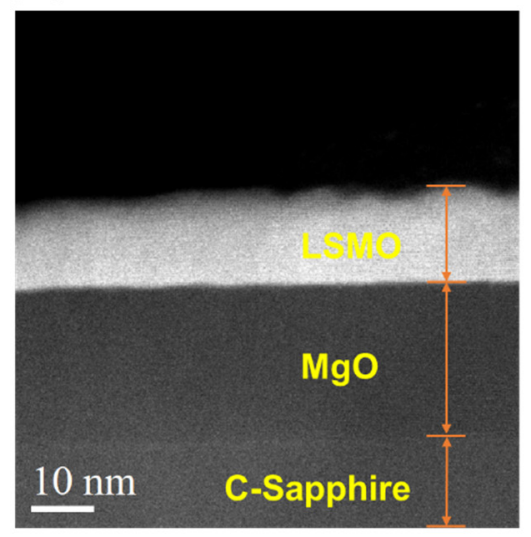

(b)

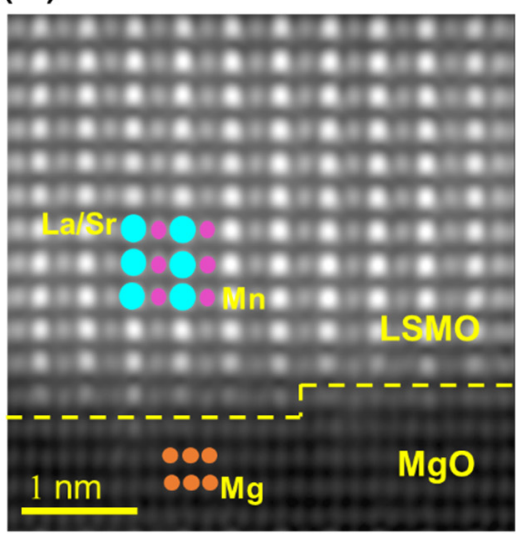

(c)

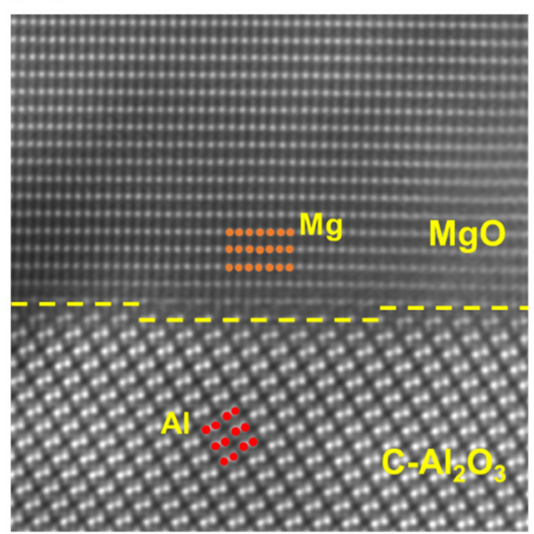

Figure 1. (a) A representative HAADF image of LSMO thin film grown on the $\mathrm{c}-\mathrm{Al}_{2} \mathrm{O}_{3}$ substrate where $\mathrm{MgO}$ is the buffer layer. Atomic resolution HAADF image showing the interface between the (b) LSMO thin film and the MgO buffer layer, (c) the $\mathrm{MgO}$ buffer layer, and $\mathrm{c}-\mathrm{Al}_{2} \mathrm{O}_{3}$ substrate.

Subsequent investigations were performed focusing on understanding the highly resolved atomic arrangement and electronic structure insights of individual interfaces of $\mathrm{LSMO} / \mathrm{MgO}$ and $\mathrm{MgO} / \mathrm{c}-\mathrm{Al}_{2} \mathrm{O}_{3}$. Figure $2 \mathrm{a}$ shows the HAADF image revealing the interface between the LSMO and $\mathrm{MgO}$ films. Figure $2 \mathrm{~b}-\mathrm{d}$ represent electron diffraction spots from the respective film and interface. The electron diffraction spots show epitaxial matching of $(2 \overline{2} 0)_{\mathrm{LSMO}} \|(2 \overline{2} 0)_{\mathrm{MgO}}$. Figure $2 \mathrm{e}$ further illustrates an atomic-resolution HAADF image of the $\mathrm{LSMO} / \mathrm{MgO}$ interface indicating the formation of dislocations with periodicity. It is evident from the Figure $2 \mathrm{e}$ that the dislocation terminates at the LSMO/MgO interface with the 4/5 lattice plane periodically which confirms the heterostructure following the DME paradigm in this study. It is important to note here that the lattice mismatch between the matching planes of $\mathrm{MgO}$ and LSMO is estimated to be $\sim 7.7 \%$, given the $\mathrm{d}$-spacing of $(110)_{\mathrm{MgO}}$ and (110) $\mathrm{LSMO}$ is $0.297 \mathrm{~nm}$ and $0.2739 \mathrm{~nm}$. The epitaxial growth of such a large 
lattice misfit ( $>7 \%$ ) between two materials, such as MgO and LSMO, is explained by DME, which illustrates that the large mismatch favors the dislocation formation at the periodic interval at a critical film thickness. These dislocations glide to the interface and allow the formation of relaxed epitaxial film growth [18,31-34]. In addition, a Burger circuit formation has been constructed at the $\mathrm{LSMO} / \mathrm{MgO}$ interface to identify the dislocation core, as shown in Figure 2e along with inverse fast Fourier transform (IFFT) analysis. The Burger vector shows the displacement of half a unit in the $\mathrm{MgO}$ buffer layer. Figure $2 \mathrm{f}$ shows the corresponding IFFTs along with the magnified HAADF images of the dislocation cores. It is clear from the images that the four lattice planes of LSMO are aligned with the five lattice planes of $\mathrm{MgO}$ periodically at the interface. The observed extra half plane in $\mathrm{MgO}$ causes the lattice distortion keeping the LSMO atomic column at equidistance. Additionally, it is observed that interdiffusion between $\mathrm{Mg}$ atoms from $\mathrm{MgO}$ and $\mathrm{Mn}$ atom from LSMO takes place to facilitate the lattice relaxation as there is an extra atom counted in the first LSMO layer at the dislocation core of these misfit dislocations. Based on the atom intensity in the HAADF image, one could eliminate the possibility of La atom diffusion across the interface. This is an important finding as such atomic rearrangement could alter the density of states, providing the traps or recombination centers for electrons and holes, thus directly affecting the electronic properties of the system [35]. The change in the density of states is directly correlated with the energy-loss function seen in the electron energy-loss spectroscopy which will be subsequently discussed in this study. These observations have been previously seen in other heterostructure systems such as $\mathrm{ZnO} / \mathrm{c}-\mathrm{Al}_{2} \mathrm{O}_{3}$ where the $\mathrm{Z}^{\mathrm{n}}$ atoms were rearranged at the core of misfit dislocations and diffused into $c-\mathrm{Al}_{2} \mathrm{O}_{3}$ substrate lattice [36].

(a)

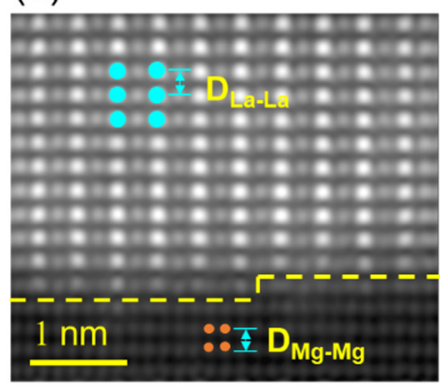

(e)

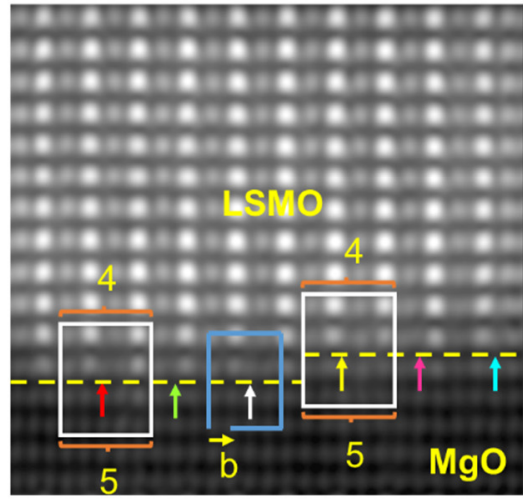

(b)

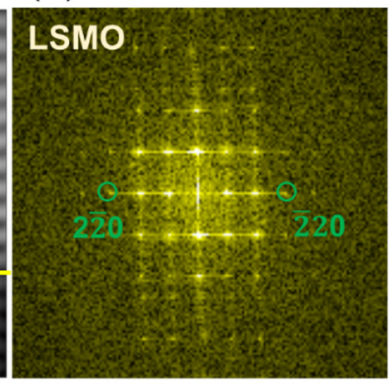

(f)
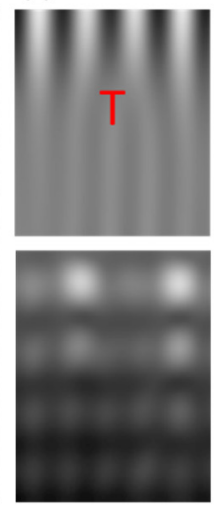

(c)

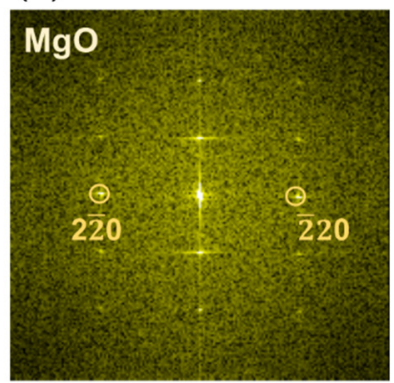

(d)

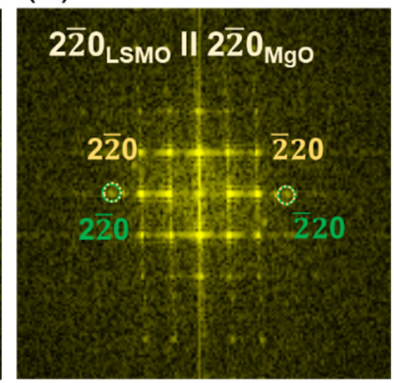

Figure 2. (a) HAADF image of LSMO over MgO showing the defined La-La and Mg-Mg bond length, (b-d) shows electron diffraction spots for the respective film, (e) HAADF image showing a 4/5 planes lattice matching and the dislocation periodicity, and (f) IFFTs along (110) with the magnified images of dislocation cores. Vertical arrows of different colors point to the extra-half planes at each dislocation core. The corresponding matching domains were bracketed with their sizes noted by the number of the LSMO and MgO lattice planes, respectively. A Burgers circuit is applied on a dislocation core to identify the Burgers vector along the edge dislocation. 
To estimate the atomic displacement at/near the interface of LSMO and $\mathrm{MgO}$, a script-based computational quantification is subsequently performed on the HAADF image data that identifies the atomic position coordinates based on the intensity of the atoms [37-40]. This quantification analysis provides a two-dimensional array of atomic positions. Figure $3 \mathrm{a}-\mathrm{c}$ reveals the atomic displacement maps of $\mathrm{D}_{\mathrm{La}-\mathrm{La}}$ and $\mathrm{D}_{\mathrm{Mg}-\mathrm{Mg}}$ along the in-plane and out-of-plane directions, respectively. Atomic spacing along the horizontal axis is termed as "in-plane" direction, whereas atomic spacing along the vertical axis is termed as "out-of-plane" direction. The change in the atomic bond length of La-La $\left(\mathrm{D}_{\mathrm{La}-\mathrm{La}}\right)$ and $\mathrm{Mg}-\mathrm{Mg}\left(\mathrm{D}_{\mathrm{Mg}-\mathrm{Mg}}\right)$ has been calculated with respect to the atomic positions of $\mathrm{Mg}$ atoms in $\mathrm{MgO}$ to understand the pseudomorphic growth of LSMO film at the interface. The atomic displacement map in the in-plane direction shows the presence of residual strain at the interface after the formation of misfit dislocations. The maximum atomic displacement is obtained along the in-plane direction is $\sim 0.006 \mathrm{~nm}$, whereas the maximum atomic displacement in the out-of-plane is $\sim 0.002 \mathrm{~nm}$, which appears more relaxed.

(a)

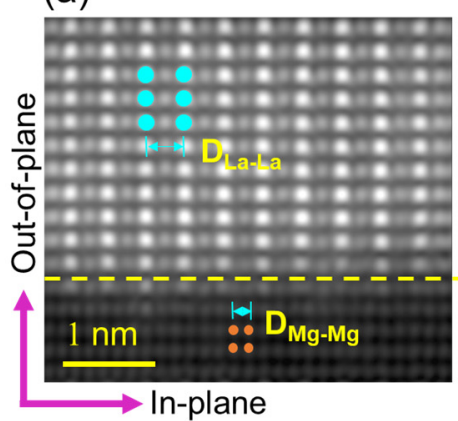

(d)

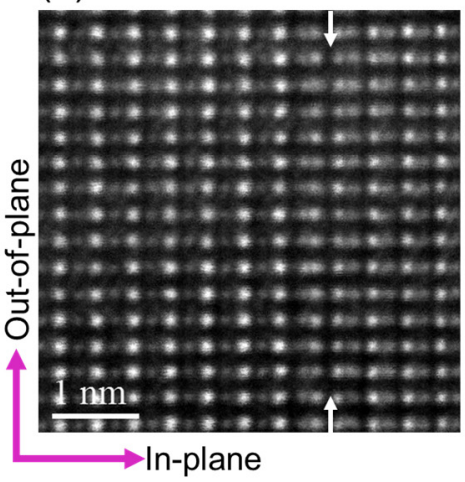

(b) In-plane

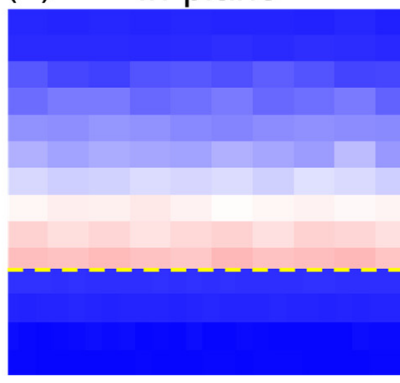

(e) $D_{\text {La-La }}$ (In-plane)

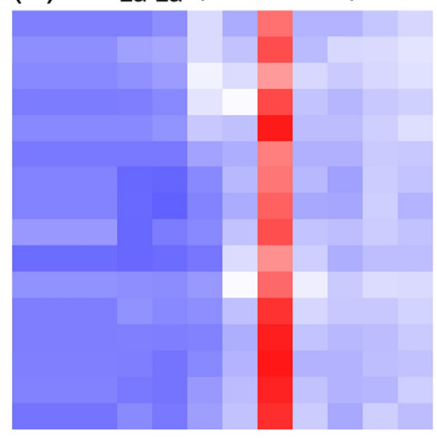

(c) Out-of-plane

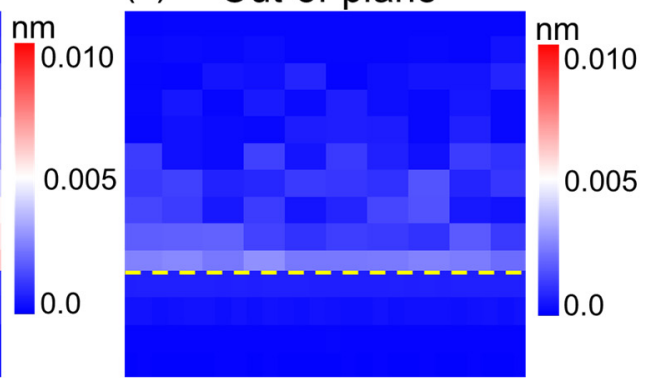

(f) $D_{\text {La-La }}$ (Out-of-plane)

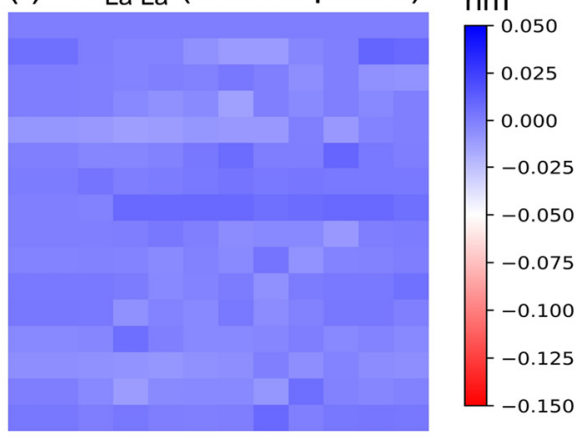

Figure 3. (a) HAADF image and (b,c) atomic bond length maps of $\mathrm{D}_{\mathrm{La}-\mathrm{La}}$ and $\mathrm{D}_{\mathrm{Mg}-\mathrm{Mg}}$ along the in-plane, and out-of-plane directions, respectively, (d) HAADF image of grown LSMO film with an indicated antiphase boundary, (e,f) atomic bond length maps of $\mathrm{D}_{\mathrm{La}-\mathrm{La}}$ along in-plane and out-of-plane directions, respectively.

Figure 3d-f further displays the atomic displacement mapping that is directly related to the increase/decrease in the bond length of La-La atoms in the LSMO thin film. The HAADF image in Figure $3 \mathrm{~d}$ shows a region in LSMO thin film containing an antiphase boundary which is a planar defect with a (220) plane missing in the ordered arrangement. The nucleation of antiphase boundaries has been seen at the step on the substrate/film. For a single step, generated antiphase boundary tends to be perpendicular to the interface, as is seen in the LSMO film [41]. Figure 3e shows the decrease in the bond length between La-La atoms in the in-plane direction at the antiphase boundary. On the other hand, there is no observable change in the out-of-plane direction.

Figure 4 further shows the plane-by-plane EELS analysis to determine the interdiffusion of atoms across the $\mathrm{LSMO} / \mathrm{MgO}$ interface and to understand the interfacial chemistry. Figure $4 \mathrm{a}$ again shows a HAADF image of LSMO film grown epitaxially on $\mathrm{MgO}$. In 
Figure $4 b$, one can observe a region of interest over which atomic-resolution EELS analysis is performed. Figure 4c,d exhibit the EELS spectra for Mn and O-K edge, respectively, from each defined plane in Figure $4 \mathrm{~b}$. It is evident from Figure $4 \mathrm{c}$ that the $\mathrm{Mn}$ in the LSMO region (layers 1-3) has a characteristic $\mathrm{L}_{32}$ absorption edge that diminishes in the $\mathrm{MgO}$ substrate (lasers 6-7) [27]. The intensity of the $\mathrm{Mn}^{-\mathrm{L}_{32}}$ peak decreases by 10 -fold in $\mathrm{MgO}$; however, it still weakly appears due to possible minor diffusion or delocalization of EELS signal. Contrarily, the O-K edge behavior transforms from the LSMO to $\mathrm{MgO}$ according to its known characteristic nature as shown in Figure 4d. In O-K spectra, a pre-peak at $526 \mathrm{eV}$ is observed in the LSMO region (layers 1-4), whereas no pre-peak is observed in the $\mathrm{MgO}$ region (layers 6-7). The evident pre-peak in the LSMO region indicates the stronger Mn-O hybridization. An additional observation worth noting is that the LSMO region (layers 1-3) has no post-peaks at $555 \mathrm{eV}$, as indicated in the Figure 4d whereas the $\mathrm{MgO}$ region has noticeable post-peak (layers 6-7). Both LSMO and $\mathrm{MgO}$ contribute to the O-K edge in close proximity at the interface (layers 4-5) due to interdiffusion, resulting in layers 4-5 displaying both pre-peaks and post-peaks.

(a)

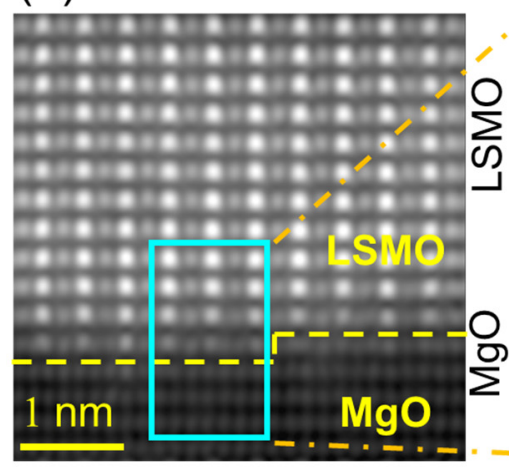

(b)

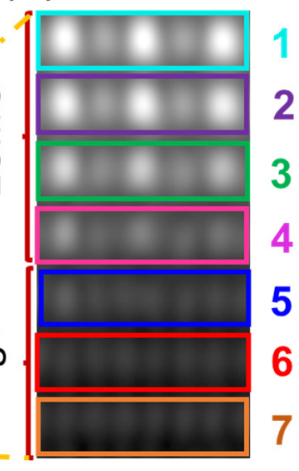

(c) Manganese peak

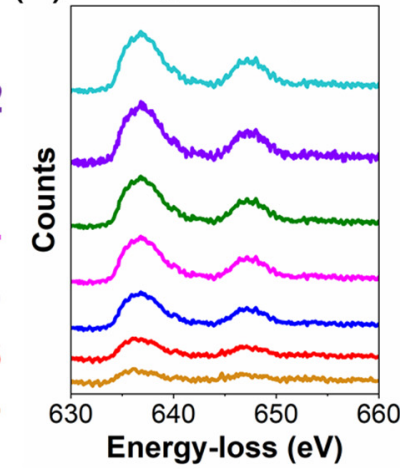

(d) Oxygen peak

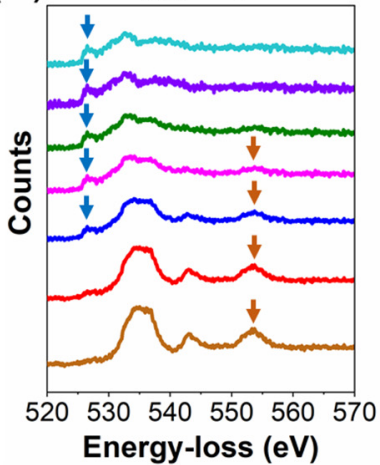

Figure 4. (a,b) Atomic-resolution HAADF image of LSMO grown on $\mathrm{MgO},(\mathbf{c}, \mathbf{d})$ atomic plane-by-plane EELS spectra for $\mathrm{Mn}$ and $\mathrm{O}-\mathrm{K}$ edge within the LSMO and $\mathrm{MgO}$ corresponding to planes shown in (b).

We further analyzed the interface between $\mathrm{MgO}$ and $\mathrm{c}-\mathrm{Al}_{2} \mathrm{O}_{3}$ substrate to appreciate the atomic-scale characteristics of this interface. The atomic-resolution HAADF image reveals the sharp interface between $\mathrm{MgO}$ and $\mathrm{c}-\mathrm{Al}_{2} \mathrm{O}_{3}$, as shown in Figure $5 \mathrm{a}$. Figure $5 \mathrm{~b}-\mathrm{d}$ demonstrate fast Fourier transform (FFT) from the respective film and the interface illustrating the diffraction spots from the individual crystal structures. The electron diffraction spots show epitaxial matching of $(2 \overline{2} 0)_{\mathrm{MgO}} \|(3 \overline{3} 0)_{\mathrm{Al}_{2} \mathrm{O}_{3}}$ (in Figure $5 \mathrm{~d}$ ). The $\mathrm{d}$-spacing of $(2 \overline{2} 0)$ in $\mathrm{MgO}$ and $(3 \overline{3} 0)$ in $\mathrm{c}-\mathrm{Al}_{2} \mathrm{O}_{3}$ are $0.1491 \mathrm{~nm}$ and $0.1374 \mathrm{~nm}$ give rise to a lattice misfit of $\sim 8.5 \%$ in the $\mathrm{MgO}$ film. This leads to the nucleation of misfit dislocations with a 12/13 plane matching between $\mathrm{MgO}$ and $\mathrm{c}-\mathrm{Al}_{2} \mathrm{O}_{3}$ following the DME paradigm. As shown in Figure $5 \mathrm{e}$, these results are consistent with the experimental finding where periodic misfit dislocations are indicated with an average 12/13 lattice plane matching, confirming the validity of DME in this system. Figure $5 \mathrm{f}$ presents the respective inverse FFT images of various dislocation cores. The presence of an extra half plane in the $c-\mathrm{Al}_{2} \mathrm{O}_{3}$ causes lattice distortion, whereas the $\mathrm{MgO}$ buffer layer atomic columns maintain an equidistant column with relaxed lattice planes. The HAADF image reveals the step with atomic scale height at both interfaces rather than maintaining the same starting plane. This represents possible interdiffusion along the incident beam directions. The rise in the atomic step can shift the interfacial contact which changes the dislocation core configuration accordingly. The change in the configuration of the dislocation core contributes to the possible interfacial interaction between the film, buffer layer, and substrate. In addition, interdiffusion induces the compositional disparity at the interface, thus hampering the dislocation core spacing in addition to the periodicity. Interestingly, the interdiffusion most seemingly occurred at a 
position slightly away from the dislocation cores. Despite having the dislocation core at the $\mathrm{LSMO} / \mathrm{MgO}$ and $\mathrm{MgO} / \mathrm{c}-\mathrm{Al}_{2} \mathrm{O}_{3}$ interface, the absence of defects such as pores confirms the excellent quality of deposited LSMO film and the $\mathrm{MgO}$ buffer layer.

(a)

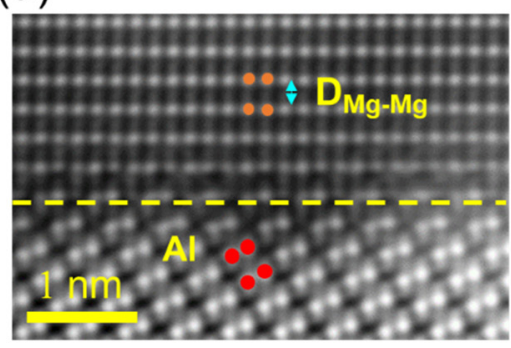

(e)

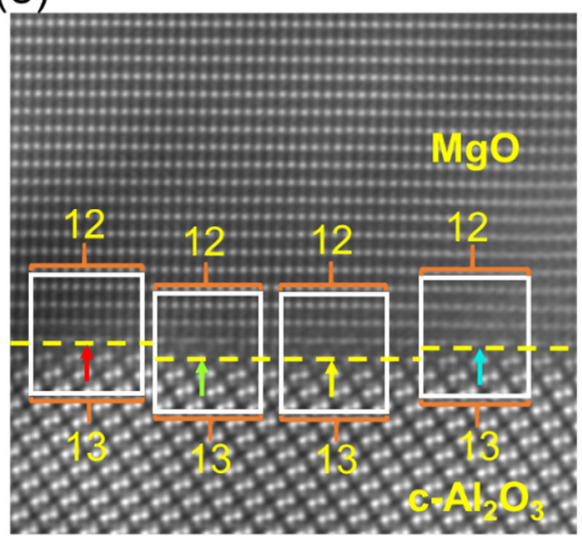

(b)

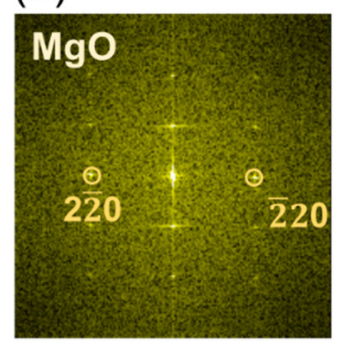

(f)
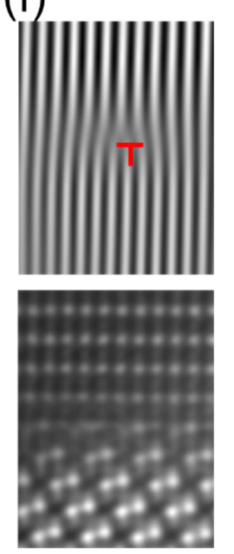

(c)

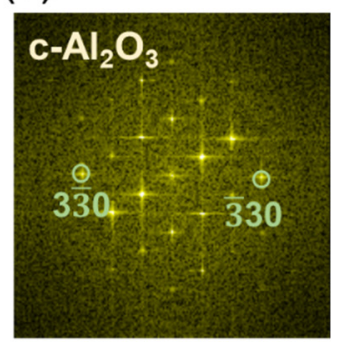

(d)

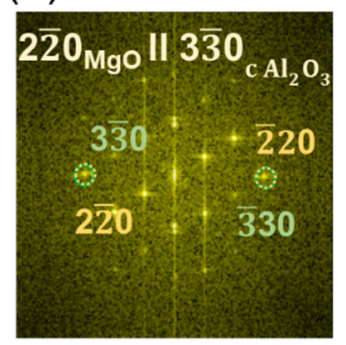

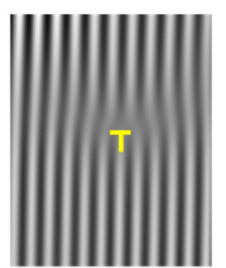

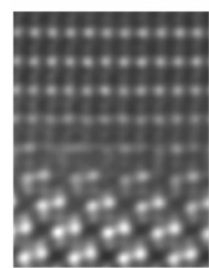

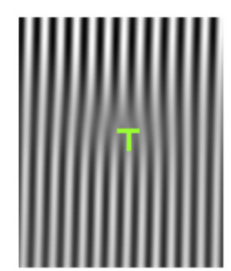

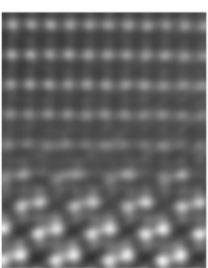

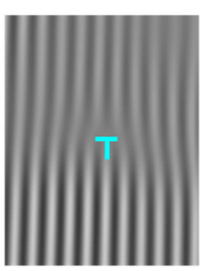

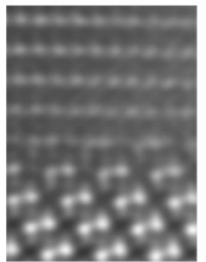

Figure 5. (a) HAADF image of $\mathrm{MgO}$ film grown on $\mathrm{c}-\mathrm{Al}_{2} \mathrm{O}_{3} . \mathrm{Mg}$ and $\mathrm{Al}$ atoms are indicated in orange and red colors. (b-d) Electron diffraction spots shown for the respective film, (e) HAADF image revealing periodic dislocation formation at the $\mathrm{MgO}$ and $\mathrm{c}-\mathrm{Al}_{2} \mathrm{O}_{3}$ interface with $12 / 13$ planes lattice matching, (f) IFFTs along (110) with magnified images of dislocation cores.

Script-based computational quantification is performed on the HAADF image as shown in Figure 6a. This computational quantification approach bears similarity with the analysis shown in Figure 3. Here, the atomic bond length of $\mathrm{Dx} \mathrm{Mg}-\mathrm{Mg} / \mathrm{D}_{\mathrm{Al}-\mathrm{Al}}$, and $\mathrm{Dz}_{\mathrm{Mg}-\mathrm{Mg}} / \mathrm{D}_{\mathrm{Al}-\mathrm{Al}}$ is investigated. These atomic bond length maps are shown in Figure $6 \mathrm{~b}, \mathrm{c}$, respectively. The relative color uniformity of the pixels, in Figure $6 b, c$, indicates relaxation of the deposited $\mathrm{MgO}$ film, maintaining the epitaxial matching of $(2 \overline{2} 0)_{\mathrm{MgO}} \|(3 \overline{3} 0)_{\mathrm{Al}_{2} \mathrm{O}_{3}}$.

(a)

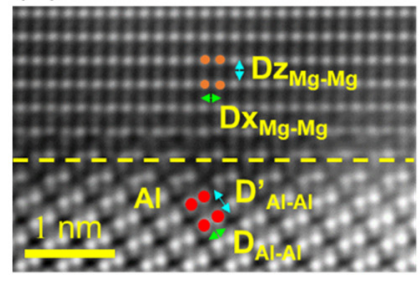

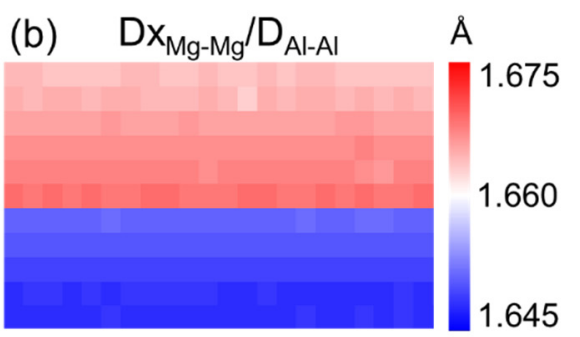

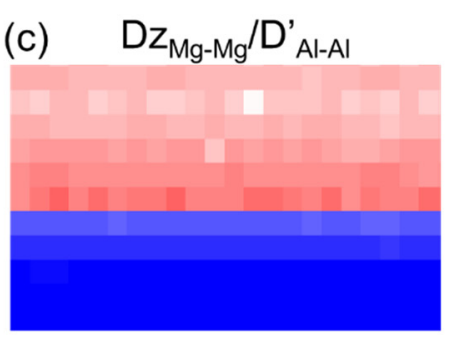

$\AA$

Figure 6. (a) HAADF image containing $\mathrm{MgO} / \mathrm{c}-\mathrm{Al}_{2} \mathrm{O}_{3}$ interface, $(\mathbf{b}, \mathbf{c})$ atomic bond length maps of $\mathrm{Dx} \mathrm{Mg}_{\mathrm{Mg}} / \mathrm{D}_{\mathrm{Al}-\mathrm{Al}}$, and $\mathrm{Dz}_{\mathrm{Mg}-\mathrm{Mg}} / \mathrm{D}_{\mathrm{Al}-\mathrm{Al}}$, respectively.

Figure 7a shows a HAADF image of the MgO buffer layer film grown epitaxially on $\mathrm{c}-\mathrm{Al}_{2} \mathrm{O}_{3}$. Figure $7 \mathrm{~b}$ shows a magnified HAADF image revealing possible interdiffusion at the interface of $\mathrm{MgO}$ and $\mathrm{c}-\mathrm{Al}_{2} \mathrm{O}_{3}$. To further investigate the interface, a detailed plane-by- 
plane EELS analysis observing the nature of O-K edge is performed, as shown in Figure 7c. The main peak of O-K edge broadens as it transfers from $\mathrm{MgO}$ to $\mathrm{c}-\mathrm{Al}_{2} \mathrm{O}_{3}$. Based on the nature of the $\mathrm{O}-\mathrm{K}$ absorption edge, it is evident that layers 1-2 are characteristic of $\mathrm{MgO}$ and layers $5-7$ of $\mathrm{c}-\mathrm{Al}_{2} \mathrm{O}_{3}$. The arrows marked at $543 \mathrm{eV}$ indicate the characteristic $\mathrm{O}-\mathrm{K}$ post-peak in the $\mathrm{MgO}$ region, whereas there is no evidence of this post-peak in the c- $\mathrm{Al}_{2} \mathrm{O}_{3}$ region. Layers 3-4 indicate the interdiffusion between the $\mathrm{MgO}$ and $\mathrm{c}-\mathrm{Al}_{2} \mathrm{O}_{3}$, as the spectrum shows characteristics of both $\mathrm{MgO}$ and c- $\mathrm{Al}_{2} \mathrm{O}_{3}$ in O-K edge. Overall, the investigations suggest that, in the large misfit system of $\mathrm{MgO} / \mathrm{c}-\mathrm{Al}_{2} \mathrm{O}_{3}$, strain is relaxed by the formation of misfit dislocations; however, we observe an interdiffusion within two monolayers at the interface.

(a)

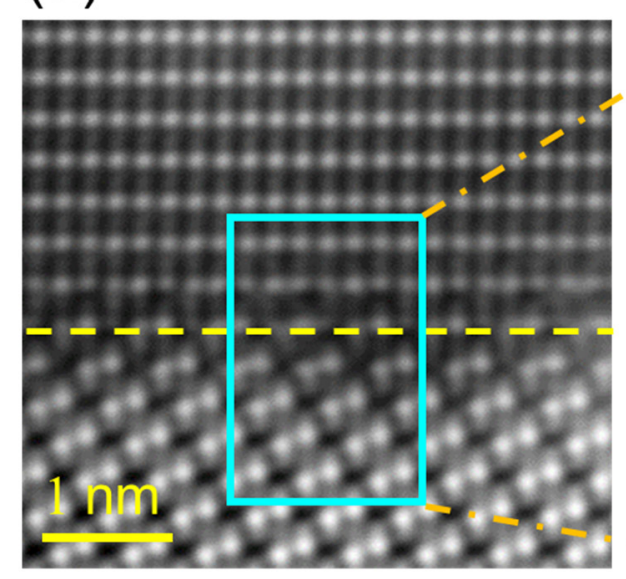

(b)

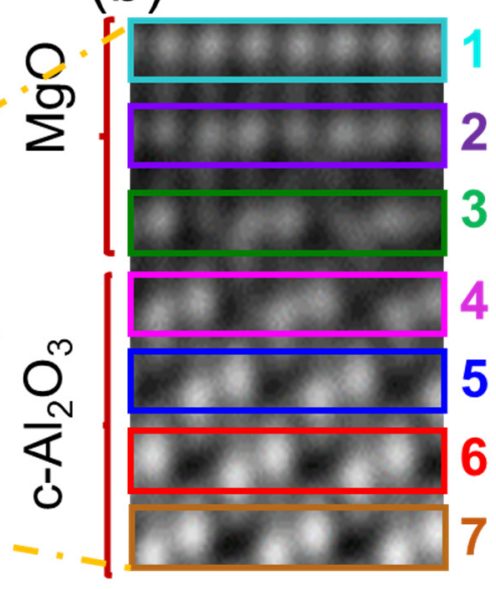

(c) Oxygen peak

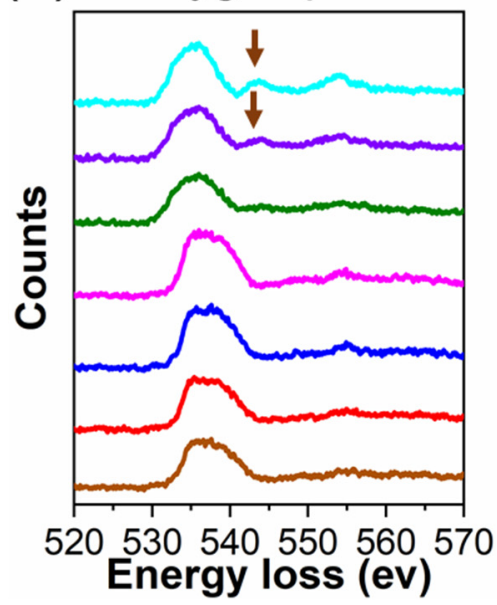

Figure 7. (a,b) Atomic-resolution HAADF image of $\mathrm{MgO}$ grown on $\mathrm{c}-\mathrm{Al}_{2} \mathrm{O}_{3}$, (c) plane-by-plane EELS spectra of O-K from the $\mathrm{MgO}$, and $\mathrm{c}-\mathrm{Al}_{2} \mathrm{O}_{3}$ corresponding to planes shown in $(\mathbf{b})$.

\section{Conclusions}

In this research, we have utilized atomic-resolution STEM imaging together with EELS analysis to recognize the characteristics of the heterogeneous interface of the $\mathrm{LSMO} / \mathrm{MgO}$ and $\mathrm{MgO} / \mathrm{c}-\mathrm{Al}_{2} \mathrm{O}_{3}$ system. Each system shows excellent consistency with the DME paradigm accompanied by misfit dislocations configurations. In both cases, periodic misfit dislocations were observed with $4 / 5$ and $12 / 13$ plane matching, respectively, for $\mathrm{LSMO} / \mathrm{MgO}$ and $\mathrm{MgO} / \mathrm{c}-\mathrm{Al}_{2} \mathrm{O}_{3}$ interfaces. Further investigation of the heterogeneous interface reveals geometrical (atomic height step) and compositional (interdiffusion) changes, thus affecting the interface chemistry and dislocation core structure. The characterization and experimental observations bolster a clearer understanding of the heterogeneous interface and defects in structures on an atomic scale. These findings support an opportunity to tune the next generation of devices.

Author Contributions: Conceptualization, R.S. and J.N.; methodology, S.M., A.K.G., B.H.B., V.S. and R.S.; software, S.M., A.K.G., B.H.B., V.S. and R.S.; validation, R.S. and J.N.; writing-original draft preparation, S.M. and A.K.G.; writing-review and editing, S.M., A.K.G., R.S. and J.N.; supervision, R.S. and J.N. All authors have read and agreed to the published version of the manuscript.

Funding: R.S. acknowledges the support of faculty start-up funding at Oklahoma State University. Institutional Review Board Statement: Not applicable.

Informed Consent Statement: Not applicable.

Data Availability Statement: Not applicable. 
Acknowledgments: The electron microscopic data acquisition in this research was conducted at the Center for Nanophase Materials Sciences, which is a DOE Office of Science User Facility. Authors also want to thank Daniel Rasic for growing the heterostructures and John Prater for useful discussions.

Conflicts of Interest: The authors declare no conflict of interest.

\section{References}

1. Queisser, H.J.; Haller, E.E. Defects in Semiconductors: Some Fatal, Some Vital. Am. Assoc. Adv. Sci. 1998, 281, 945-950. [CrossRef] [PubMed]

2. Mahajan, S. Defects in semiconductors and their effects on devices. Acta Mater. 2000, 48, 137-149. [CrossRef]

3. Dagotto, E. Complexity in Strongly Correlated Electronic Systems. Science 2005, 309, 257-262. [CrossRef] [PubMed]

4. Reiner, J.W.; Walker, F.J.; Ahn, C.H. Atomically Engineered Oxide Interfaces. Science 2009, 323, 1018-1019. [CrossRef]

5. Jia, C.L.; Thust, A.; Urban, K. Atomic-scale analysis of the oxygen configuration at a $\mathrm{SrTiO}_{3}$ dislocation core. Phys. Rev. Lett. 2005, 95, 1-4. [CrossRef] [PubMed]

6. Szot, K.; Speier, W.; Bihlmayer, G.; Waser, R. Switching the electrical resistance of individual dislocations in single-crystalline $\mathrm{SrTiO}_{3}$. Nat. Mater. 2006, 5, 312-320. [CrossRef] [PubMed]

7. Schlom, D.G.; Chen, L.-Q.; Eom, C.-B.; Rabe, K.M.; Streiffer, S.K.; Triscone, J.-M. Strain Tuning of Ferroelectric Thin Films. Annu. Rev. Mater. Res. 2007, 37, 589-626. [CrossRef]

8. Bowen, M.; Bibes, M.; Barthélémy, A.; Contour, J.P.; Anane, A.; Lema1tre, Y.; Fert, A. Nearly total spin polarization in $\mathrm{La}_{2 / 3} \mathrm{Sr}_{1 / 3} \mathrm{MnO}_{3}$ from tunneling experiments. Appl. Phys. Lett. 2003, 82, 233-235. [CrossRef]

9. Hwang, H.Y.; Cheong, S.-W.; Radaelli, P.G.; Marezio, M.; Batlogg, B. Lattice Effects on the Magnetoresistance in Doped LaMnO 3 . Phys. Rev. Lett. 1995, 75, 914-917. [CrossRef] [PubMed]

10. Rasic, D.; Sachan, R.; Temizer, N.K.; Prater, J.; Narayan, J. Oxygen Effect on the Properties of Epitaxial (110) $\mathrm{La}_{0.7} \mathrm{Sr}_{0.3} \mathrm{MnO}_{3}$ by Defect Engineering. ACS Appl. Mater. Interfaces 2018, 10, 21001-21008. [CrossRef] [PubMed]

11. Kim, B.; Kwon, D.; Song, J.H.; Hikita, Y.; Kim, B.G.; Hwang, H.Y. Finite size effect and phase diagram of ultra-thin $\mathrm{La}_{0.7} \mathrm{Sr}_{0.3} \mathrm{MnO}_{3}$. Solid State Commun. 2010, 150, 598-601. [CrossRef]

12. Tsui, F.; Smoak, M.C.; Nath, T.K.; Eom, C.B. Strain-dependent magnetic phase diagram of epitaxial $\mathrm{La}_{0.67} \mathrm{Sr}_{0.33} \mathrm{MnO}_{3}$ thin films. Appl. Phys. Lett. 2000, 76, 2421-2423. [CrossRef]

13. Vailionis, A.; Boschker, H.; Siemons, W.; Houwman, E.P.; Blank, D.H.A.; Rijnders, G.; Koster, G. Misfit strain accommodation in epitaxial $\mathrm{ABO}_{3}$ perovskites: Lattice rotations and lattice modulations. Phys. Rev. B Condens. Matter Mater. Phys. 2011, 83, 1-10. [CrossRef]

14. Sun, J.Z.; Abraham, D.W.; Rao, R.A.; Eom, C. Thickness-dependent magnetotransport in ultrathin manganite films. Appl. Phys. Lett. 1999, 74, 3017-3019. [CrossRef]

15. Boschker, H.; Kautz, J.; Houwman, E.P.; Siemons, W.; Blank, D.H.A.; Huijben, M.; Koster, G.; Vailionis, A.; Rijnders, G. HighTemperature Magnetic Insulating Phase in Ultrathin $\mathrm{La}_{0.67} \mathrm{Sr}_{0.33} \mathrm{MnO}_{3}$ Films. Phys. Rev. Lett. 2012, 109, 157207. [CrossRef]

16. Sandiumenge, F.; Santiso, J.; Balcells, L.; Konstantinovic, Z.; Roqueta, J.; Pomar, A.; Espinos, J.P.; Martínez, B. Competing Misfit Relaxation Mechanisms in Epitaxial Correlated Oxides. Phys. Rev. Lett. 2013, 110, 107206. [CrossRef] [PubMed]

17. Narayan, J.; Larson, B.C. Domain epitaxy: A unified paradigm for thin film growth. J. Appl. Phys. 2003, 93, 278-285. [CrossRef]

18. Narayan, J.; Tiwari, P.; Chen, X.; Singh, J.; Chowdhury, R.; Zheleva, T. Epitaxial growth of TiN films on (100) silicon substrates by laser physical vapor deposition. Appl. Phys. Lett. 1992, 61, 1290-1292. [CrossRef]

19. Yang, S.; Kuang, W.; Liou, Y.; Tse, W.; Lee, S.; Yao, Y. Growth and characterization of $\mathrm{La}_{0.7} \mathrm{Sr}_{0.3} \mathrm{MnO}_{3}$ films on various substrates. J. Magn. Magn. Mater. 2004, 268, 326-331. [CrossRef]

20. Špankova, M.; Chromik, Š.; Vávra, I.; Sedláčková, K.; Lobotka, P.; Lucas, S.; Stanček, S. Epitaxial LSMO films grown on MgO single crystalline substrates. Appl. Surf. Sci. 2007, 253, 7599-7603. [CrossRef]

21. Wang, C.; Zhu, Y.; Li, L.; Shen, Q.; Zhang, L. Epitaxial growth and transport property of $\mathrm{La}_{0.9} \mathrm{Sr}_{0.1} \mathrm{MnO}_{3}$ thin films deposited on $\mathrm{MgO}, \mathrm{LaAlO}_{3}$ and $\mathrm{SrTiO}_{3}$ substrates. J. Alloy. Compd. 2017, 693, 832-836. [CrossRef]

22. Štrbík, V.; Reiffers, M.; Dobročka, E.; Soltys, J.; Špankova, M.; Chromik, Š. Epitaxial LSMO thin films with correlation of electrical and magnetic properties above 400K. Appl. Surf. Sci. 2014, 312, 212-215. [CrossRef]

23. Ranno, L.; Llobet, A.; Hunt, M.; Pierre, J. Influence of substrate temperature on magnetotransport properties of thin films of $\mathrm{La}_{0.7} \mathrm{Sr}_{0.3} \mathrm{MnO}_{3}$. Appl. Surf. Sci. 1999, 138-139, 228-232. [CrossRef]

24. Chu, M.W.; Szafraniak, I.; Scholz, R.; Harnagea, C.; Hesse, D.; Alexe, M.; Gösele, U. Impact of misfit dislocation on the po-larization instability of epitaxial nanostructured ferroelectric perovskites. Nat. Mater. 2004, 3, 87-90. [CrossRef] [PubMed]

25. Erni, R.; Rossell, M.D.; Kisielowski, C.; Dahmen, U. Atomic-Resolution Imaging with a Sub-50-pm Electron Probe. Phys. Rev. Lett. 2009, 102, 096101. [CrossRef] [PubMed]

26. Klenov, D.O.; Stemmer, S. Contributions to the contrast in experimental high-angle annular dark-field images. Ultramicroscopy 2006, 106, 889-901. [CrossRef] [PubMed]

27. Rasic, D.; Sachan, R.; Prater, J.; Narayan, J. Structure-property correlations in thermally processed epitaxial LSMO films. Acta Mater. 2019, 163, 189-198. [CrossRef]

28. Moatti, A.; Sachan, R.; Gupta, S.; Narayan, J. Vacancy-Driven Robust Metallicity of Structurally Pinned Monoclinic Epitaxial VO 2 Thin Films. ACS Appl. Mater. Interfaces 2019, 11, 3547-3554. [CrossRef] [PubMed] 
29. Moatti, A.; Sachan, R.; Narayan, J. Mechanism of strain relaxation: Key to control of structural and electronic transitions in $\mathrm{VO}_{2}$ thin-films. Mater. Res. Lett. 2019, 8, 16-22. [CrossRef]

30. Krivanek, O.; Chisholm, M.F.; Nicolosi, V.; Pennycook, T.J.; Corbin, G.J.; Dellby, N.; Murfitt, M.F.; Own, C.S.; Szilagyi, Z.S.; Oxley, M.P.; et al. Atom-by-atom structural and chemical analysis by annular dark-field electron microscopy. Nature 2010, 464, 571-574. [CrossRef] [PubMed]

31. Moatti, A.; Sachan, R.; Prater, J.; Narayan, J. Control of Structural and Electrical Transitions of $\mathrm{VO}_{2}$ Thin Films. ACS Appl. Mater. Interfaces 2017, 9, 24298-24307. [CrossRef] [PubMed]

32. Rasic, D.; Sachan, R.; Chisholm, M.F.; Prater, J.; Narayan, J. Room Temperature Growth of Epitaxial Titanium Nitride Films by Pulsed Laser Deposition. Cryst. Growth Des. 2017, 17, 6634-6640. [CrossRef]

33. Gupta, S.; Sachan, R.; Narayan, J. Evidence of weak antilocalization in epitaxial TiN thin films. J. Magn. Magn. Mater. 2020, 498, 166094. [CrossRef]

34. Liu, X.-Y.; Arslan, I.; Arey, B.W.; Hackley, J.; Lordi, V.; Richardson, C.J.K. Perfect Strain Relaxation in Metamorphic Epitaxial Aluminum on Silicon through Primary and Secondary Interface Misfit Dislocation Arrays. ACS Nano 2018, 12, 6843-6850. [CrossRef]

35. Zhang, Z.; Yates, J.T., Jr. Band bending in semiconductors: Chemical and physical consequences at surfaces and interfaces. Chem. Rev. 2012, 10, 5520-5551. [CrossRef] [PubMed]

36. Narayan, J. Recent progress in thin film epitaxy across the misfit scale. Acta Mater. 2013, 61, 2703-2724. [CrossRef]

37. Zhang, Y.; Xue, H.; Zarkadoula, E.; Sachan, R.; Ostrouchov, C.; Liu, P.; Wang, X.-L.; Zhang, S.; Wang, T.S.; Weber, W.J. Coupled electronic and atomic effects on defect evolution in silicon carbide under ion irradiation. Curr. Opin. Solid State Mater. Sci. 2017, 21, 285-298. [CrossRef]

38. Gupta, A.K.; Arora, G.; Aidhy, D.S.; Sachan, R. $\sum 3$ Twin Boundaries in $\mathrm{Gd}_{2} \mathrm{Ti}_{2} \mathrm{O}_{7}$ Pyrochlore: Pathways for Oxygen Migration. ACS Appl. Mater. Interfaces 2020, 12, 45558-45563. [CrossRef] [PubMed]

39. Aidhy, D.S.; Sachan, R.; Zarkadoula, E.; Pakarinen, O.; Chisholm, M.F.; Zhang, Y.; Weber, W.J. Fast ion conductivity in strained defect-fluorite structure created by ion tracks in $\mathrm{Gd}_{2} \mathrm{Ti}_{2} \mathrm{O}_{7}$. Sci. Rep. 2015, 5, 16297. [CrossRef] [PubMed]

40. Gupta, A.K.; Gupta, S.; Sachan, R. Laser Irradiation Induced Atomic Structure Modifications in Strontium Titanate. JOM 2021, 1-8. [CrossRef]

41. Wang, Z.; Guo, H.; Shao, S.; Saghayezhian, M.; Li, J.; Fittipaldi, R.; Vecchione, A.; Siwakoti, P.; Zhu, Y.; Zhang, J.; et al. Designing antiphase boundaries by atomic control of heterointerfaces. Proc. Natl. Acad. Sci. USA 2018, 115, 9485-9490. [CrossRef] [PubMed] 